\title{
Unusual Case of Midline Middle Skull Base Lymphoma Mimicking as Invasive Pituitary Adenoma
}

\author{
Harish Naik ${ }^{1}$ Pravin Survashe ${ }^{1}$ Vernon Velho ${ }^{1}$ Anuj Bhide ${ }^{1} \quad$ Laxmikant Bhople $^{1}$ Amrita Guha ${ }^{2}$
}

${ }^{1}$ Department of Neurosurgery, J. J. Group of Hospitals and Grant Medical College, Mumbai, Maharashtra, India

2Department of Radiodiagnosis, J. J. Group of Hospitals and Grant Medical College, Mumbai, Maharashtra, India

\begin{abstract}
Address for correspondence Dr. Harish Naik, MCh, Department of Neurosurgery, J.J Group of Hospitals and Grant Medical College, Mumbai 400008, Maharashtra, India (e-mail: haryadoc@gmail.com).
\end{abstract}

\begin{abstract}
Keywords

- non-Hodgkin's lymphoma

- NK/T-cell clival lymphoma

Non-Hodgkin's lymphoma (NHL) is a rare tumor of the skull base. As the incidence of primary central nervous system (CNS) lymphoma has increased, atypical presentations involving the skull base are being reported. However, isolated involvement of middle skull base, that too predominantly the clivus and parasellar region, is rarely seen. We present a case of middle-age woman with midline skull base lesion located in the sella with invasion of the ventral part of upper part of clivus (posterior clinoid) and also the parasellar region causing involvement of optic and abducens nerve with preserved hormonal functions. She was operated endoscopically for partial resection of the lesion. Histopathology turned out to be non-Hodgkin's lymphoma of NK/T-cell variety. So far NK/T-cell lymphoma of the sella with invasion into the clivus has never been reported in literature to the best of our knowledge.
\end{abstract}

\section{Introduction}

Lymphoma is the malignant monoclonal proliferation of lymphoid cells in discrete tissue masses of the immune system, such as lymph nodes, spleen, and bone marrow. Primary skull base lymphoma arising from the sella with invasion of the ventral part of upper part of clivus (posterior clinoid) and also the parasellar region is quite a rare entity. In immunocompetent patients with no predisposing history, the disease may be least suspected. Especially considering the increasing use of cranial base surgical approaches to resect tumors in these regions, it is important for neurosurgeons to be aware of atypical and unusual pathologic abnormalities that may be encountered.

\section{Case Report}

A 35-year-old woman presented to our outpatient department with 6-month history of diminishing vision on left side with diplopia. On clinical examination she left lateral rectus paresis with diminished vision (finger counting at $2 \mathrm{ft}$ ). Funduscopy showed optic atrophy on left side and normal optic disc on right.

On radiologic evaluation, magnetic resonance imaging (MRI) of the brain revealed $2.4-\times 2.9-\times 2.1-\mathrm{cm}$-size lesion in the sellar and suprasellar, which was hyperintense on T1-weighted (T1W) ( Fig. 1A) and iso- to hypointense on T2 images ( - Fig. 1B) with heterogeneous contrast enhancement ( - Fig. 2A, B). Superolaterally, it was compressing the optic chiasma; laterally extending into cavernous sinuses more on left side and posteriorly involving clivus (posterior clinoid) and extending into prepontine cistern. Pituitary gland could not be seen separately. On viewing computed tomographic (CT) scan of the brain, it was evident that the lesion was causing erosion and involvement of the clivus, sellar floor, sphenoid wall, and bilateral cavernous sinuses (-Fig. 2C). Surprisingly, her hormonal profile was normal in spite of received

January 17, 2017

accepted after revision

April 2, 2017

published online

May 19, 2017
DOI https://doi.org/

10.1055/s-0037-1603327.

ISSN 2277-954X.
@2018 Neurological Surgeons'

Society of India
License terms

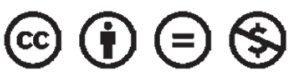


A
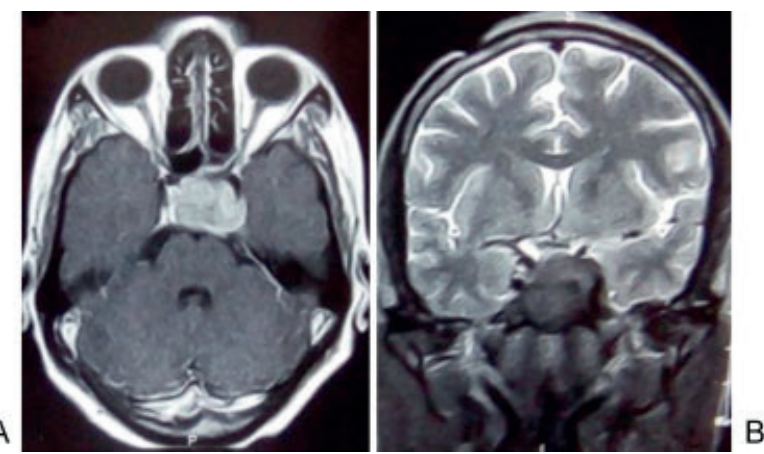

Fig. 1 (A, B) A 2.4- × 2.9- ×2.1-cm-size lesion in sellar and suprasellar that was hyperintense on T1W sequence and iso- to hypointense on T2W images.

such a gross destruction of the sella and parasellar region indicating pathology of nonpituitary origin.

During surgery, endoscopic endonasal transsphenoidal approach was used. There was evidence of hypertrophy of the sellar floor, and lesion was reddish gray in color. Debulking of the lesion was done and the sellar floor reconstructed. Intraoperative frozen-section cytology was suggestive of round cell tumor. On histologic examination the slide was composed of plasmacytoid cells with eccentrically placed nucleus with abundant cytoplasm and evenly distributed chromatin ( - Fig 3). Pituitary parenchyma was seen separately and uninvolved. Immunohistochemistry revealed strong positivity for CD45/CD56 and CD36, suggesting natural killer/T-cell lymphoma (NK/TCL).

The patient recovered well in postoperative period. Her vision and lateral rectus paresis improved to an acceptable level. She was further investigated for lymphoma staging. The patient was immunocompetent and human immunodeficiency syndrome (HIV) negative with normal complete blood count. Bone marrow biopsy was negative for lymphoma cells. No sinonasal or pharyngeal primary lesion was seen in CT of the head and neck. CT of the chest and abdomen did not show significant lymphadenopathy or hepatosplenomegaly. Clinicopathologic and radiographic evaluation was thus negative for extracranial lymphoma,

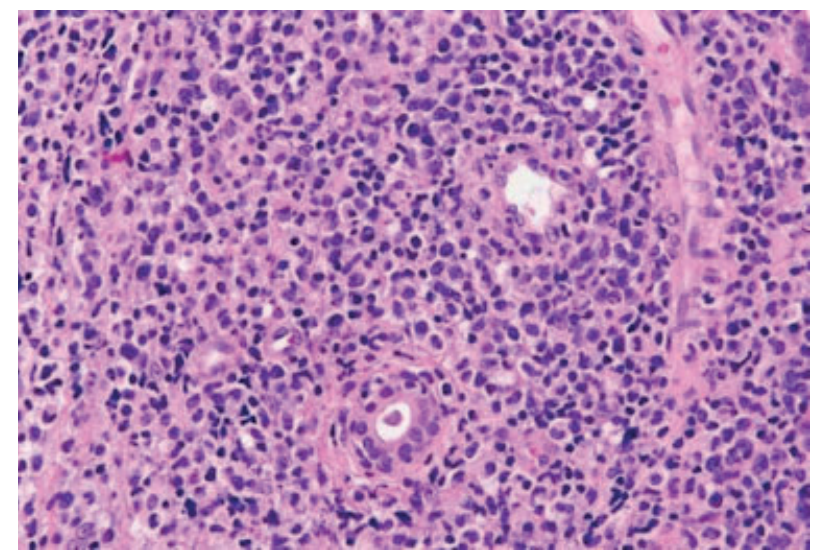

Fig. 3 Histopathology confirmed a natural killer cell pituitary lymphoma.

and a diagnosis of primary central nervous system (CNS) NK/T-cell lymphoma was done. Postoperative MRI images ( - Fig. 4A, B) showed adequate tumor decompression and evidence of small residual lesion adherent to the left cavernous sinus. The patient was then treated with combined radiotherapy and systemic chemotherapy.

\section{Discussion}

Primary CNS lymphoma is an uncommon neoplasm, historically representing approximately $1 \%$ of primary brain tumors. ${ }^{1}$ However, its incidence has more than tripled in the United States and United Kingdom since the early 1980s. ${ }^{1}$ Primary CNS lymphoma represents approximately $3 \%$ of intracranial neoplasms in patients with acquired immunodeficiency syndromes. ${ }^{1,2}$ The incidence of primary CNS lymphoma has been increasing in both immunologically competent and immunologically compromised patients for uncertain reasons. ${ }^{3}$

This increase was initially thought to be caused solely by the increasing incidence of HIV-1 infection and the relationship between HIV-l-induced immunosuppression and the development of primary CNS lymphoma. Further epidemiologic studies have demonstrated, however, that this increase is apparent in both HIV-l-infected and uninfected populations alike.
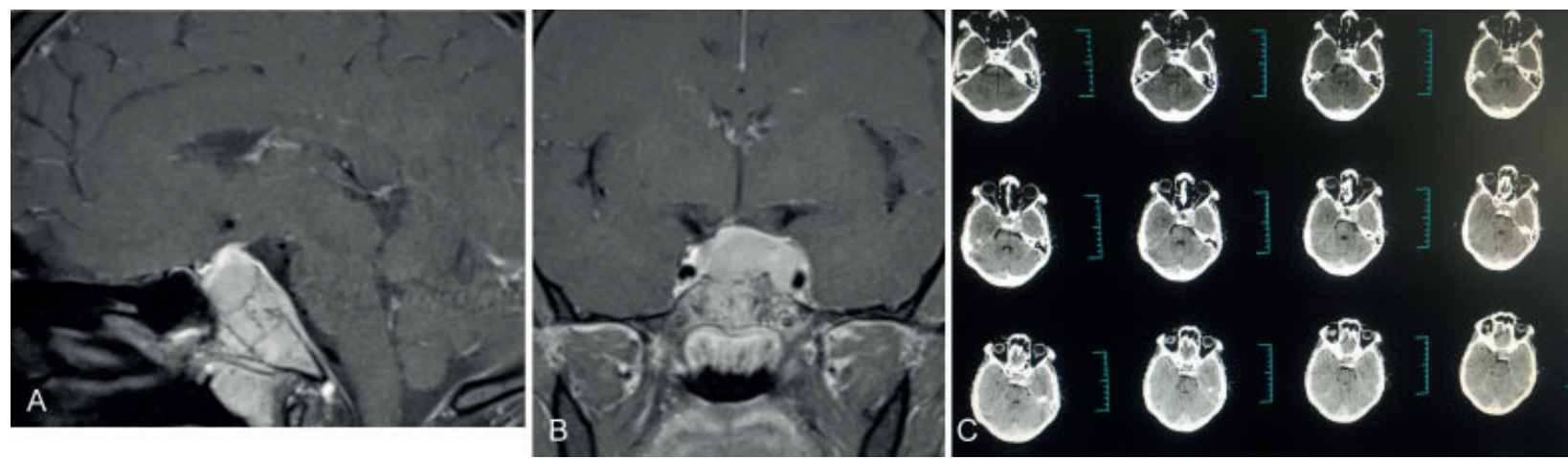

Fig. 2 (A, B) Postcontrast saggital and coronal T1 MPRAGE sequence showing a large ill-defined irregular heterogeneously enhancing mass lesion in the sellar-suprasellar region displacing the optic chasm superiorly with infiltration of the clivus. Laterally extending into cavernous sinus on left side . Pituitary gland could not be seen separately. (C) CT scan image showing involvement of the clivus by the lesion. 

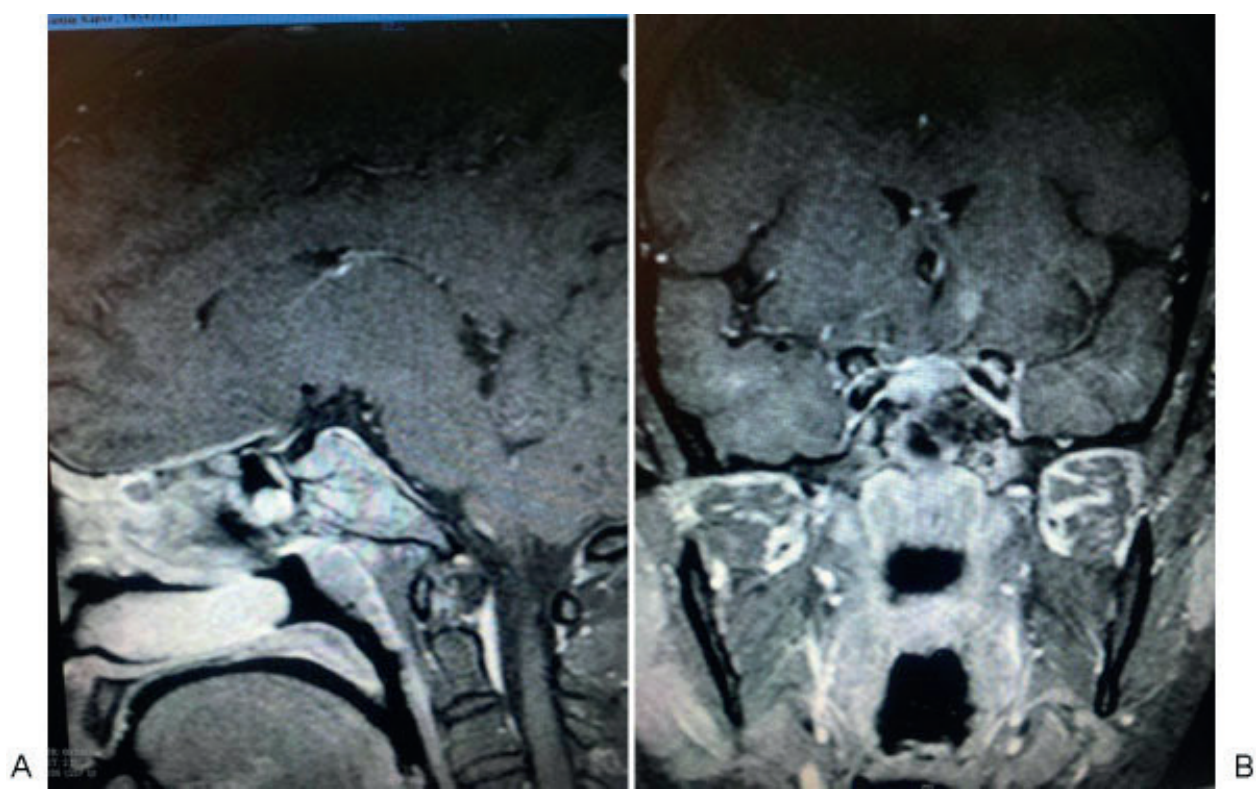

Fig. 4 (A, B) Postoperative MRI saggital and coronal T1 MPRAGE sequence (postcontrast) showing adequate decompression with small residual lesion adherent to the left cavernous sinus.

Primary CNS lymphoma represents $1 \%$ of all lymphomas and less than $5 \%$ of all non-Hodgkin's lymphomas (NHL). ${ }^{4,5}$ Among primary CNS lymphomas, 98\% comprise monoclonal B-cell NHL, whereas primary CNS T-cell lymphomas are extremely rare. Large cell lymphoma of B-cell origin is the most common subtype of malignant non-Hodgkin's primary lymphoma that primarily involves the CNS.

Primary CNS lymphoma most commonly arises from the deep hemispheric periventricular white matter; other expected sites include the corpus callosum, cerebellum, orbits, and cranial nerves. Lymphoma as primary infiltration of the skull base, especially the clivus, is unusual and rare. ${ }^{6}$ Lymphomas of the skull base, including the clivus, are classified as extracerebral lymphomas. Roman-Goldstein et al described three cases of cavernous sinus lymphoma, with involvement of the sphenoid body, as atypical intracerebral (CNS) lymphoma, emphasizing that as the incidence of primary CNS lymphoma increases, there will be an increased likelihood of atypical presentations of this tumor entity leading to diagnostically challenging tumor entities as encountered in our case. ${ }^{7}$

Primary CNS lymphoma is rarely considered in the differential diagnosis of cranial base lesions at these sites, and cranial neuropathies in the setting of lymphoma usually suggest leptomeningeal spread of systemic lymphoma rather than primary CNS disease. Especially considering the increasing use of cranial base surgical approaches to resect tumors in these regions, it is important for neurosurgeons to be aware of atypical and unusual pathologic abnormalities such as lymphoma that may be encountered.

Pituitary adenoma is by far the most common sellar mass, although craniopharyngioma, Rathke's cleft cyst, dermoid, epidermoid, germinoma, metastasis, meningioma, arachnoid cyst, sarcoidosis, tuberculosis, histiocytosis, lymphocytic hypophysitis, schwannoma, infundibular glioma, and cavernous carotid artery aneurysm are included in the differential diagnosis of sellar and parasellar disease. ${ }^{89}$

Normal adult clivus consists of low- and high-intensity portions mixed in various proportions in T1W images (due to varying amounts of fatty marrow), and it is isointense to the pons in T2W images..$^{10}$ In comparison, typical MRI findings of skull base lymphoma are: (1) isointensity of the tumor compared with the gray matter of the brain; (2) homogenous gadolinium-enhancement of the lesion on T1W images; (3) hypointensity on T2W MRI; and (4) encasement of vessels without narrowing of the lumen..$^{10,11}$ However, a diagnosis of lymphoma cannot be made solely from clinical findings and imaging. ${ }^{7}, 12$

A current literature search revealed few other cases of B-cell NHL involving clivus. Okamoto et al presented a case of 69-yearold man presenting with symptoms of progressive headaches and diplopia. ${ }^{13} \mathrm{~A}$ transsphenoidal excisional biopsy was done. Jung et al reported a case of clival lesion in which MRI-guided biopsy was done, which diagnosed it to be a malignant lymphoma of B-cell origin. He recommended biopsy of the clival lesion prior to extensive cranial base surgery. ${ }^{14}$

As for lymphoma, systemic chemotherapy remains the appropriate treatment as opposed to surgical resection. ${ }^{4}$ Extranodal NK/TCLs are aggressive and are associated with a poor clinical outcome. The cumulative probability of survival in patients with extranodal NK/TCLs at 5 years ranges from 37.9 to $45.3 \%{ }^{4}$

Treatment of NK/TCL of the nasal type has consisted of radiotherapy, with or without multiagent chemotherapy; however, no effective treatment regimen has been identified. ${ }^{15}$ 
In our case, initial working radiologic diagnosis was invasive pituitary adenoma; however, the patient had no clinical signs of pituitary involvement. Her hormonal profile was within normal range. Our patient had isolated involvement of optic and sixth nerve on left side, and the pituitary gland was seen separate from the lesion, which further added to the diagnostic dilemma. Moreover, 98\% of primary CNS lymphomas comprise monoclonal B-cell NHL, whereas primary CNS NK/TCLs observed in our case are extremely rare.

\section{Conclusion}

Diffuse large B-cell lymphoma of the clivus is an uncommon condition, and the primary location of the lymphoma in the sella with invasion of the upper part of clivus without any other nodal site is also rare as encountered in our case. It is of practical importance to recognize lymphoma as a possible cause of nasopharyngeal lesion and of cranial nerve dysfunction; even if uncommon, it should always be included in the differential diagnosis of skull base aggressive neoplasm. Moreover, because neoplasm such as lymphoma can be successfully treated with chemotherapy, it is strongly recommended that a histologic diagnosis be made before instituting .Especially considering the increasing use of cranial base surgical approaches to resect tumors in these regions, it is important for neurosurgeons to be aware of atypical and unusual pathologic abnormalities that may be encountered. We conclude that lymphomas, although uncommon, should be included in the differential diagnosis of aggressive neoplasms of the skull base and the paranasal sinuses.

\section{References}

1 Jellinger KA, Paulus W. Primary central nervous system lymphomas-an update.J Cancer Res Clin Oncol 1992;119(01):7-27
2 Maher EA, Fine HA. Primary CNS lymphoma. Semin Oncol 1999;26(03):346-356

3 Eby NL, Grufferman S, Flannelly CM, Schold SC Jr, Vogel FS, Burger PC. Increasing incidence of primary brain lymphoma in the US. Cancer 1988;62(11):2461-2465

4 Mohile NA, Abrey LE. Primary central nervous system lymphoma. Neurol Clin 2007;25(04):1193-1207, xi

5 Chim CS, Ma SY, Au WY, et al. Primary nasal natural killer cell lymphoma: long-term treatment outcome and relationship with the International Prognostic Index. Blood 2004;103(01):216-221

6 Hans FJ, Reinges MH, Nolte K, Reipke P, Krings T. Primary lymphoma of the skull base. Neuroradiology 2005;47(07):539-542

7 Roman-Goldstein SM, Jones A, Delashaw JB, McMenomey S, Neuwelt EA. Atypical central nervous system lymphoma at the cranial base: report of four cases. Neurosurgery 1998;43(03):613-615, discussion 615-616

8 Landman RE, Wardlaw SL, McConnell RJ, Khandji AG, Bruce JN, Freda PU. Pituitary lymphoma presenting as fever of unknown origin. J Clin Endocrinol Metab 2001;86(04):1470-1476

9 Kaufmann TJ, Lopes MB, Laws ER Jr, Lipper MH. Primary sellar lymphoma: radiologic and pathologic findings in two patients. AJNR Am J Neuroradiol 2002;23(03):364-367

10 Kimura F, Kim KS, Friedman H, Russell EJ, Breit R. MR imaging of the normal and abnormal clivus. AJNR Am J Neuroradiol 1990;11(05):1015-1021

11 Han MH, Chang KH, Kim IO, Kim DK, Han MC. Non-Hodgkin lymphoma of the central skull base: MR manifestations. J Comput Assist Tomogr 1993;17(04):567-571

12 Nakatomi H, Sasaki T, Kawamoto S, Fujimaki T, Furuya K, Kirino T. Primary cavernous sinus malignant lymphoma treated by gamma knife radiosurgery: case report and review of the literature. Surg Neurol 1996;46(03):272-278, discussion 278-279

13 Okamoto S, Kurimoto M, Hirashima Y, et al. [Systemic non-Hodgkin lymphoma initially presented with visual disturbance due to intrasellar lymphoma-a case report] [in Japanese] No Shinkei Geka 2001;29(01):59-63

14 Jung CS, Zimmermann M, Seifert V. Clivus lymphoma. Acta Neurochir (Wien) 2004;146(05):533-534

15 Cheung MM, Chan JK, Wong KF. Natural killer cell neoplasms: a distinctive group of highly aggressive lymphomas/leukemias. Semin Hematol 2003;40(03):221-232 